\title{
The Incidence of Induced Abortion in Malawi
}

\author{
By Brooke A. \\ Levandowski, \\ Chisale Mhango, \\ Edgar Kuchingale, \\ Juliana Lunguzi, \\ Hans Katengeza, \\ Hailemichael \\ Gebreselassie and \\ Susheela Singh
}

Brooke A.

Levandowski is senior research and evaluation associate, Ipas, Chapel Hill, NC, USA. At the time this study was conducted, Chisale Mhango was director, Reproductive Health Services, Ministry of Health, Blantyre, Malawi. Edgar Kuchingale is lecturer, Department of Obstetrics and Gynecology, Malawi

College of Medicine, Blantyre. Juliana Lunguzi is a midwifery advisor, United

Nations Population Fund, Lilongwe, Malawi. Hans

Katengeza is reproductive health officer,

Reproductive Health

Unit, Malawi Ministry

of Health, Lilongwe. Hailemichael

Gebreselassie is senior research advisor, Ipas, Nairobi, Kenya. Susheela Singh is vice president for research, Guttmacher Institute, New York.

CONTEXT: Abortion is legally restricted in Malawi, and no data are available on the incidence of the procedure.

METHODS: The Abortion Incidence Complications Methodology was used to estimate levels of induced abortion in Malawi in 2009. Data on provision of postabortion care were collected from 166 public, nongovernmental and private health facilities, and estimates of the likelihood that women who have abortions experience complications and seek care were obtained from 56 key informants. Data from these surveys and from the 2010 Malawi Demographic and Health Survey were used to calculate abortion rates and ratios, and rates of pregnancy and unintended pregnancy.

RESULTS: Approximately 18,700 women in Malawi were treated in health facilities for complications of induced abortion in 2009. An estimated 67,300 induced abortions were performed, equivalent to a rate of 23 abortions per 1,000 women aged 15-44 and an abortion ratio of 12 per 100 live births. The abortion rate was higher in the North (35 per 1,000) than in the Central region or the South (20-23 per 1,000). The unintended pregnancy rate in 2010 was 139 per 1,000 women aged 15-44, and an estimated 52\% of all pregnancies were unintended.

CONCLUSIONS: Unsafe abortion is common in Malawi. Interventions are needed to help women and couples avoid unwanted pregnancy, reduce the need for unsafe abortion and decrease maternal mortality.

International Perspectives on Sexual and Reproductive Health, 2013, 39(2):88-96, doi: 10.1363/3908813

Unsafe abortion is a public health concern for many developing countries. The World Health Organization has estimated that 21.6 million unsafe abortions and 47,000 abortion-related deaths occurred globally in 2008. ${ }^{1}$ The vast majority (98\%) of unsafe abortions take place in developing regions. The risk of death from unsafe abortion is highest in Sub-Saharan Africa, where an estimated 520 deaths occur per 100,000 unsafe abortion procedures, compared with about 30 per 100,000 in the developed world. ${ }^{1}$

Unsafe abortion is one of the major factors contributing to high levels of maternal mortality (pregnancy-related deaths). ${ }^{2}$ Sub-Saharan Africa has the highest maternal mortality ratio in the world-an estimated 640 deaths per 100,000 live births in 2008, of which $14 \%$ were due to abortion complications. ${ }^{1,3}$ According to the 2010 Malawi Demographic and Health Survey (DHS), the average maternal mortality ratio during the seven-year period before the survey was 675 deaths per 100,000 live births (range, 570-780). ${ }^{4}$ Although a comparison of maternal mortality ratios for 2004 and 2010 (984 and 675, respectively) shows a substantial decline, the rate of maternal deaths remains very high in Malawi. ${ }^{3,5}$ A study at a large facility in Malawi indicated that 24\% of maternal deaths in 1999 were attributable to postabortion complications. ${ }^{6}$

Studies have shown that banning or severely restricting abortion does not reduce abortion rates, but instead affects the safety of the procedure. In regions where most women live under restrictive abortion laws, the estimated abor- tion incidence is higher than it is in regions comprising countries with liberal abortion laws. ${ }^{1,7}$ In countries with restrictive laws, not only do some women die from unsafe abortion, but many others suffer long-term health consequences, including chronic pain and sterility. ${ }^{8}$

In Malawi, abortion is legal only when performed to save a pregnant woman's life. ${ }^{9}$ Despite this restrictive law, a study by the Family Planning Association of Malawi revealed that women in Malawi seek abortion for a variety of reasons, including poverty, unplanned pregnancy, coercion, shame and fear of being forced out of school. ${ }^{10}$ In a 2004 study of Malawian adolescents, more than one-third of 15-19-year-olds and about one-fifth of 12-14-year-olds reported having one or more close friends who had tried to end a pregnancy. ${ }^{11}$ As only a few Malawian studies on abortion and related morbidity and mortality have been conducted in the past decade (all of them small-scale, hospital-based studies), up-to-date national data on abortion are greatly needed. ${ }^{6,12}$ To fill this important gap, and to provide evidence that can inform policymakers about the magnitude and health impact of unsafe abortion, we sought to estimate the incidence of induced abortion in Malawi.

\section{METHODS}

This study builds on data collection approaches and methodologies used in previous abortion incidence and morbidity studies conducted in South Africa, Uganda, Kenya and Ethiopia. ${ }^{13-17}$ Specifically, we used the Abortion 


\begin{tabular}{|c|c|c|c|c|c|c|c|c|c|}
\hline \multirow[t]{2}{*}{ Facility type } & \multirow[t]{2}{*}{$\begin{array}{l}\text { No. of } \\
\text { facilities }\end{array}$} & \multirow{2}{*}{$\begin{array}{l}\text { No.of } \\
\text { facilities in } \\
\text { sampling } \\
\text { frame* }\end{array}$} & \multirow{2}{*}{$\begin{array}{l}\% \text { of } \\
\text { target } \\
\text { facilities } \\
\text { sampled }\end{array}$} & \multirow{2}{*}{$\begin{array}{l}\text { No.of } \\
\text { sampled } \\
\text { facilities }\end{array}$} & \multirow{2}{*}{$\begin{array}{l}\text { No. of sampled } \\
\text { facilities } \\
\text { providing } \\
\text { postabortion } \\
\text { care }\end{array}$} & \multicolumn{2}{|c|}{$\begin{array}{l}\text { Prospective Morbidity } \\
\text { Survey }\end{array}$} & \multicolumn{2}{|c|}{ Health Facilities Survey } \\
\hline & & & & & & $\begin{array}{l}\text { No.of } \\
\text { participating } \\
\text { facilities }\end{array}$ & $\begin{array}{l}\% \text { of } \\
\text { facilities } \\
\text { participating }\end{array}$ & $\begin{array}{l}\text { No.of } \\
\text { partici- } \\
\text { pating } \\
\text { facilities }\end{array}$ & $\begin{array}{l}\% \text { of } \\
\text { facilities } \\
\text { participating }\end{array}$ \\
\hline Public hospital & 56 & 50 & 100.0 & 50 & 47 & 47 & 100 & 47 & 100 \\
\hline Public health center & 405 & 64 & 100.0 & 64 & 46 & 44 & 96 & 45 & 98 \\
\hline NGO hospital & 41 & 33 & 100.0 & 33 & 30 & 27 & 90 & 29 & 97 \\
\hline NGO health center & 152 & 41 & 100.0 & 41 & 35 & 35 & 100 & 34 & 97 \\
\hline Private hospital & 2 & 2 & 100.0 & 2 & 2 & 2 & 100 & 2 & 100 \\
\hline Private clinic & 237 & $23 \overline{7}$ & 33.3 & 79 & 6 & 6 & 100 & 5 & 83 \\
\hline All & 893 & 427 & na & 269 & 166 & 161 & 97 & 162 & 98 \\
\hline
\end{tabular}

Incidence Complications Methodology (AICM), which incorporates data from two component studies, the Health Facilities Survey and the Health Professionals Survey. The methodology was adapted to utilize additional data from a third source, the Prospective Morbidity Survey, on the number of women treated for abortion complications. ${ }^{18,19}$ The details of these surveys, as applied in Malawi, are described below.

This study received ethical approval from the Malawi National Health Sciences Research Committee. Data for the Prospective Morbidity Survey were collected as an extension of routine medical record keeping performed by postabortion care providers. The data collection tool closely resembled a patient medical chart, except that names and other identifying information were not recorded. Informed consent was obtained from participants in the Health Facilities and Health Professionals Surveys.

\section{Sampling Frame}

To generate the list of facilities in the sample, we followed a three-step process. First, we compiled a list of all health facilities in Malawi; next, we identified the facilities on the list that were potential providers of postabortion care; and finally, we further reduced the list to public and nongovernmental (NGO) facilities known to provide postabortion care.

To create the initial list, the research team, in collaboration with the Malawi Ministry of Health and the Medical Council of Malawi, used the November 2008 edition of the Malawi Government Gazette, which listed all licensed public, NGO and private hospitals and clinics along with their registration number, address, district, type (such as government health facility or Christian Health Association of Malawi facility) and director. This list was supplemented by lists of facilities associated with Banja La Mtsogolo* and the Ministry of Health's Reproductive Health Unit to create a national list of 893 facilities.

To restrict this list to facilities that potentially provided postabortion care, we took several steps. First, facilities that clearly did not provide maternal health care, such as the Malawi Defense Force health facilities and certain types of specialized clinics (e.g., mental health clinics), were elimi- nated. Lists of remaining facilities were given to Ministry of Health zonal health supervisors, ${ }^{\dagger}$ who indicated that 427 facilities on the list were likely to be providing postabortion care. We then used a single-stage stratified sampling approach to select a nationally representative sample of these facilities. We included in the sample all 188 public and NGO facilities that were thought to provide postabortion care (including public referral and teaching hospitals, district hospitals, public health centers, NGO hospitals and NGO health centers) and both private hospitals. The 237 listed private clinics were stratified by the country's five zones; we used systematic random sampling to select one-third (79) of these facilities. In total, 269 facilities were selected for the study (Table 1).

The research team contacted all facilities by telephone to obtain the name of (and contact information for) the main provider of postabortion care and to invite him or her to participate in the study. During these conversations, the research team confirmed that 166 of the 269 facilities were currently providing postabortion care. Of these 166 facilities, 93 were public ( 46 health centers, 43 secondary facilities and four tertiary facilities), 65 were run by NGOs (35 health centers and 30 secondary facilities) and eight were private (six clinics and two tertiary facilities).

\section{Data Sources}

The Prospective Morbidity Survey, Health Facilities Survey and Health Professionals Survey were pretested in July 2009; data collection ran from August to October 2009.

- Prospective Morbidity Survey. The main provider of postabortion care at each participating facility attended a twoday training program on the data collection tool. Providers who worked at larger facilities trained other providers of postabortion care at their facilities once they returned. The Prospective Morbidity Survey was fielded for 30 days at each facility. For every woman who presented for post-

*Banja La Mtsogolo is a nongovernmental organization affiliated with Marie Stopes International.

†Zonal health supervisors are Ministry of Health employees who are assigned to one of Malawi's five geopolitical zones; they have frequent contact with the government and NGO health facilities in their zone. These individuals were able to obtain valuable, up-to-date information on the services provided at facilities in their zone. 
TABLE 2. Indicators of postabortion care provision, by type of facility, Malawi, 2009

\begin{tabular}{|c|c|c|c|c|c|c|c|}
\hline Indicator & $\begin{array}{l}\text { Public } \\
\text { hospitals }\end{array}$ & $\begin{array}{l}\text { Public } \\
\text { health } \\
\text { centers }\end{array}$ & $\begin{array}{l}\text { NGO } \\
\text { hospitals }\end{array}$ & $\begin{array}{l}\text { NGO } \\
\text { health } \\
\text { centers }\end{array}$ & $\begin{array}{l}\text { Private } \\
\text { hospitals }\end{array}$ & $\begin{array}{l}\text { Private } \\
\text { clinics }\end{array}$ & $\begin{array}{l}\text { All } \\
(95 \% \mathrm{Cl})\end{array}$ \\
\hline \multicolumn{8}{|l|}{ No. of women receiving postabortion care } \\
\hline Calculated using PMS data & 13,688 & 3,215 & 4,780 & 3,855 & 61 & 1,035 & $26,634(22,596-30,674)$ \\
\hline Calculated using two HFS estimates & 16,433 & 2,541 & 4,907 & 4,950 & 132 & 1,594 & $30,557(26,098-35,016)$ \\
\hline Calculated using all of the above & 15,779 & 2,787 & 4,736 & 4,858 & 108 & 1,229 & $29,497(25,635-33,359)$ \\
\hline No. of facilities providing postabortion care & 47 & 46 & 30 & 35 & 2 & 6 & 166 \\
\hline Mean no. of women treated per facility* & 336 & 61 & 158 & 139 & 54 & 205 & 187 \\
\hline
\end{tabular}

*Among facilities that provide postabortion care. Notes: Estimates of number of abortion complications use weighted data. Notes: $\mathrm{Cl}=\mathrm{confidence}$ interval. PMS=Prospective Morbidity Survey. HFS=Health Facilities Survey.

abortion care during the data collection period, the provider recorded information on the woman's demographic characteristics, her presenting clinical signs and symptoms and the clinical care she received. Ninety-eight percent of selected facilities participated in the survey.

- Health Facilities Survey. The Health Facilities Survey was also fielded at each facility. After attending a weeklong training course on the study and its data collection tool, Ministry of Health zonal supervisors interviewed a key informant at each facility who was knowledgeable about provision of postabortion care at the facility. The informant, who was typically the facility's director or main provider of postabortion care, was asked to estimate the number of women treated for postabortion complications as inpatients and outpatients, both in the past month and in an average month. The two reference periods were used to take into account variation over time in the facility's caseload. The informant also provided information on a range of other topics, including the types of reproductive health services provided at the facility (such as manual vacuum aspiration) and details about postabortion family planning provision. Ninety-nine percent of sampled facilities participated in the study.

- Health Professionals Survey. The investigators consulted with a range of experts in the field of reproductive health in Malawi to identify potential key informants for the Health Professionals Survey. This produced a list of 123 possible respondents-health professionals who had extensive knowledge of the conditions under which women obtain abortions in Malawi. Study investigators attempted to contact each prospective participant to assess his or her availability and interest in being interviewed; 56 were successfully interviewed. Most respondents were obstetriciangynecologists (32\%), medical officers $(27 \%)$ or clinical officers (21\%); on average, they had 16 years' experience in reproductive health. Sixty-one percent of participants were currently working in one of Malawi's two major cities (Lilongwe and Blantyre), although 52\% had worked in a rural area for at least six months in the past five years. During the interviews, the experts provided three types of estimates: the percentage distribution of women who obtain abortions, according to the type of provider; the probability that women who have an abortion experience complications that require medical care, according to the type of provider; and the probability that women who experience complications obtain medical care at a health facility. Participants provided estimates for each of four subgroups (poor rural women, nonpoor rural women, poor urban women and nonpoor urban women) to capture expected social and demographic differences in women's access to abortion services and postabortion care.

- Additional data sources. To cross-check whether postabortion cases were undercounted in the Prospective Morbidity and Health Facilities Surveys, as well as to assess the completeness of logbook records, Ministry of Health zonal supervisors collected logbook data from each facility on the number of procedures completed in the 30 days prior to and during data collection for the Prospective Morbidity Survey. This information was used to conduct a validity check of the number of women who obtained postabortion care. In addition, to estimate abortion incidence and to provide contextual information on reproductive health in Malawi, we used data from the following sources: the 2008 Malawi Housing and Population Census, ${ }^{20}$ the $2006 \mathrm{Mul}$ tiple Indicator Cluster Survey, ${ }^{21}$ the 2004 and 2010 DHS, ${ }^{4,5}$ and the 2004-2005 Integrated Household Survey.22

\section{Calculation of Abortion Incidence}

In the AICM, the incidence of abortion is estimated by determining the number of women who received postabortion care at health facilities during a one-year period and then adjusting this figure to include women who had abortion complications but did not obtain care at a health facility and those who had an abortion but did not have complications (and thus did not need treatment). The number of women who received postabortion care is determined using annual postabortion care caseloads from the Prospective Morbidity and Health Facilities Surveys. Because some women who receive postabortion care have had spontaneous abortions (miscarriages), the next step is to subtract the estimated number of women who had obtained treatment for complications of spontaneous abortions from the total number of women with abortion complications; the result is the number of women treated for complications of induced abortions. Next, a factor or multiplier is generated using information obtained from the Health Professionals Survey to account for the remaining women who had an induced abortion; the multiplier can be interpreted 


\begin{tabular}{|c|c|c|c|c|c|c|}
\hline Region & $\begin{array}{l}\text { No. of women } \\
\text { treated for abortion } \\
\text { complications* }\end{array}$ & $\begin{array}{l}\text { No. of women } \\
\text { with live births }\end{array}$ & $\begin{array}{l}\text { No.of women } \\
\text { with spontane- } \\
\text { ous abortions }\end{array}$ & $\begin{array}{l}\% \text { of women } \\
\text { who deliver } \\
\text { in facilities }\end{array}$ & $\begin{array}{l}\text { No. of women treated } \\
\text { in facilities for complications } \\
\text { of spontaneous abortion }\end{array}$ & $\begin{array}{l}\text { No. of women treated in } \\
\text { facilities for complications } \\
\text { of induced abortion }\end{array}$ \\
\hline All & 29,497 & 585,095 & 19,952 & 53.8 & 10,811 & 18,686 \\
\hline North & 5,258 & 78,294 & 2,670 & 60.6 & 1,618 & 3,640 \\
\hline Central & 12,138 & 248,788 & 8,484 & 50.8 & 4,310 & 7,828 \\
\hline South & 12,101 & 258,014 & 8,798 & 55.5 & 4,883 & 7,218 \\
\hline
\end{tabular}

to mean that for every woman who obtained postabortion care, a certain number of others also had an induced abortion but did not receive or require treatment for complications. The product of the multiplier and the number of women treated for complications of induced abortion is an estimate of the number of induced abortions.

As noted earlier, our estimate of the number of women treated for abortion complications was derived from multiple data sources. Prospective Morbidity Survey caseloads during the 30-day data collection period were multiplied by 12.2 to provide the number of women receiving postabortion care in 2009. In addition, the two estimates of postabortion care caseloads obtained from the Health Facilities Survey-cases in the past month and those in the typical month-were each multiplied by 12 to produce annualized numbers. The three data points were then averaged to create a best composite estimate of the annual caseload for each facility. After weighting the data to adjust for nonparticipating facilities and for proportional sampling of private facilities, we estimate that a total of 29,500 women received postabortion care in Malawi in 2009 (Table 2).

This estimate includes both women who had induced abortions and those who had spontaneous abortions. Because of the stigma surrounding the reporting of induced abortions and the difficulty of clinically differentiating complications of spontaneous abortions from those of induced abortions, survey respondents were not asked to distinguish between the two types of abortion complication patients. Instead, the AICM uses an indirect approach to estimate the number of women treated in facilities for complications of each type of abortion.

In particular, the number of late spontaneous abortions (those that occurred at 13-21 weeks' gestation and thus would have required women to obtain facility-based care*) is estimated to be $3.41 \%$ of the number of live births, a proportion determined from clinical studies of spontaneous pregnancy loss. ${ }^{19,23,24}$ We estimated the number of births in Malawi in 2009 by applying age-specific fertility rates from the 2010 DHS (for the three-year period preceding the survey) to the number of women in the population in $2009,{ }^{\dagger}$ yielding an estimate of 585,100 live births (Table 3 ). The number of late spontaneous abortions, therefore, would have been about 19,950. However, not all women who have late spontaneous abortions obtain care at a health facility; as a proxy for the proportion who do, we used the proportion of women who gave birth at a health facility in a recent year (54\% nationally; $51-61 \%$ across regions). By applying these proportions to the number of spontaneous abortions, we estimate that 10,800 women in Malawi were treated in health facilities for complications of spontaneous abortion in 2009. Subtracting this number from the number of women treated for any abortion complications $(29,500)$ yields the number of women treated for complications of induced abortion (18,700).

To calculate the multiplier that accounts for women who did not need or receive treatment, we used estimates from Health Professionals Survey participants of the proportion of women in the four population subgroups (urban poor, urban nonpoor, rural poor and rural nonpoor) who receive postabortion care if they have an abortion. These four estimates were weighted according to the subgroups' representation among all women of reproductive age. Using data from the 2004-2005 Integrated Household Survey ${ }^{22}$ in combination with 2008 census data on urban-rural population composition, we estimate that in $2009,45 \%$ of women were rural poor, $7 \%$ were urban poor, $40 \%$ were rural nonpoor and $8 \%$ were urban nonpoor. The multiplier is the inverse of the weighted proportion of abortion recipients who were treated in health care facilities; in Malawi, this proportion was $28 \%$ and the multiplier was 3.6 (i.e., 1.0/0.28). We applied this multiplier to the number of women treated for complications of induced abortion to produce estimates of the number of women who had abortions in 2009, both for Malawi as a whole and for the country's major regions. Given that these are approximate measures of abortion incidence, we also provide upper and lower estimates by applying two alternative multipliers (2.6 and 4.6) obtained by reducing or increasing the value of the multiplier by 1.0.

\section{Validity Check}

We used data from facility logbooks provided and tracked by the Ministry of Health as a validity check of the robustness of the estimate of the annual postabortion care caseload. No special efforts were made for this study to ensure the completeness of the logbook data; the data were collected as recorded. Logbook data were available from 124

\footnotetext{
*Women who have early pregnancy loss (before 13 weeks' gestation) are not expected to need facility-based care, and losses at or beyond 22 weeks are classified as fetal deaths, not spontaneous abortions.

tTo estimate the number of women of reproductive age by age and province in 2009, we applied the annual growth rate of Malawi's population from 1998 to 2008 (2.8\%) to 2008 census data; the resulting estimate was $2,883,800$ women aged $15-44$.
} 
TABLE 4. Number of induced abortions, abortion rate and abortion ratio among women aged 15-44, by multiplier, nationally and according to region, Malawi, 2009

\begin{tabular}{|c|c|c|c|c|c|c|c|c|c|c|}
\hline \multirow[t]{3}{*}{ Region } & \multirow{3}{*}{$\begin{array}{l}\text { No. of women treated } \\
\text { for induced abortion }\end{array}$} & \multicolumn{3}{|c|}{ No. of induced abortions } & \multicolumn{3}{|c|}{ Abortion rate } & \multicolumn{3}{|c|}{ Abortion ratio } \\
\hline & & \multicolumn{3}{|c|}{ Multiplier } & \multicolumn{3}{|c|}{ Multiplier } & \multicolumn{3}{|c|}{ Multiplier } \\
\hline & & 2.6 & 3.6 & 4.6 & 2.6 & 3.6 & 4.6 & 2.6 & 3.6 & 4.6 \\
\hline All & 18,686 & 48,584 & 67,270 & 85,956 & 16.8 & 23.3 & 29.8 & 8.3 & 11.5 & 14.7 \\
\hline Northern & 3,640 & 9,464 & 13,104 & 16,744 & 25.1 & 34.8 & 44.4 & 12.1 & 16.7 & 21.4 \\
\hline Central & 7,828 & 20,353 & 28,181 & 36,009 & 16.8 & 23.3 & 29.8 & 8.2 & 11.3 & 14.5 \\
\hline Southern & 7,218 & 18,767 & 25,985 & 33,203 & 14.5 & 20.0 & 25.6 & 7.3 & 10.1 & 12.9 \\
\hline
\end{tabular}

Notes: Abortion rate is number of abortions per 1,000 women aged $15-44$. Abortion ratio is number of abortions per 100 live births.

(75\%) of the 166 facilities in the study. Zonal supervisors extracted logbook data on the number of postabortion care procedures that were recorded during the 30 days prior to data collection and the number recorded during the 30 days of data collection. The mean of these two numbers was used to represent the logbook monthly caseload, which was annualized by multiplying by 12.2 , yielding an estimate of 32,700.

For the subset of facilities with logbook data, an $\mathrm{r}^{2}$ test was used to determine the correlations of the logbook caseload with the Prospective Morbidity Survey caseload and the Health Facilities Survey estimates. The $\mathrm{r}^{2}$ test had a value of 0.9 for the comparison between logbook data and Prospective Morbidity Survey data, indicating high comparability. The test had a value of 0.7 for the comparison of logbook data with the mean of the two Health Facilities Survey estimates, and values of 0.5 and 0.7 for the comparison with the average month's and previous month's Health Facilities Study estimates, respectively, indicating lower comparability.

To test the robustness of our estimate of the number of women who obtained postabortion care at health facilities in 2009, we created a composite variable that averaged the four estimates (the Prospective Morbidity Survey caseload, the two Health Facilities Survey estimates and the logbook caseload). The resulting estimate was that 29,900 women were treated for complications ( $95 \%$ confidence interval, 24,300-35,500 women), which is almost the same as the estimate of 29,500 calculated earlier by averaging the three values obtained from the Prospective Morbidity and Health Facilities Surveys. This similarity confirms that those estimates were robust and strengthens our confidence in the validity of the data from the Prospective Morbidity and Health Facilities Surveys.

\begin{tabular}{|c|c|c|c|c|}
\hline Region & $\begin{array}{l}\text { No.of } \\
\text { pregnancies }\end{array}$ & $\begin{array}{l}\text { Pregnancy } \\
\text { rate }\end{array}$ & $\begin{array}{l}\text { Unintended } \\
\text { pregnancy rate }\end{array}$ & $\begin{array}{l}\% \text { of pregnancies that } \\
\text { are unintended }\end{array}$ \\
\hline All & 776,112 & 269 & 139 & 51.7 \\
\hline North & 108,367 & 288 & 128 & 44.6 \\
\hline Central & 329,546 & 271 & 148 & 54.3 \\
\hline South & 338,200 & 260 & 134 & 51.5 \\
\hline
\end{tabular}

Note: Pregnancy rates are per 1,000 women aged 15-44.

\section{Unintended Pregnancy}

The total number of pregnancies in 2009 was calculated by summing the estimates of the numbers of live births, induced abortions and spontaneous abortions (early or late). To estimate the number of pregnancies that end in spontaneous abortions, we used a model-based approach derived from clinical studies of pregnancy loss by gestational age, ${ }^{23,24}$ according to this model, the estimated number of pregnancy losses is equal to $20 \%$ of the number of live births (whether planned or unplanned) plus $10 \%$ of the number of induced abortions. The numbers of planned and unplanned births were calculated by applying 2010 DHS data on the percentage of births that were wanted and the percentage that were either mistimed or unwanted* to the total number of live births. Unintended pregnancies are defined as those that ended in an unplanned birth, an induced abortion or a spontaneous abortion (if the pregnancy was not planned); similarly, intended pregnancies are those that ended in a planned birth or in a spontaneous abortion (if the pregnancy was planned).

\section{Other Analyses}

Rates of abortion and hospitalization for complications of unsafe induced abortion in 2009 were estimated per 1,000 women aged 15-44. We used age-specific fertility rates from the 2010 DHS to calculate the abortion ratio, expressed as the number of abortions per 100 live births. Pregnancy rates and unintended pregnancy rates were calculated based on the number of women aged 15-44 in 2009. Data were analyzed using Stata version 11 and Excel 2007. Unweighted counts and weighted proportions are reported for Malawi as a whole as well as for the Northern, Central and Southern regions. Postabortion care caseload data from the facilities were weighted to generate estimates for a nationally representative sample of facilities providing such care.

\section{RESULTS}

\section{Postabortion Services Caseload}

From Prospective Morbidity Survey data, we calculated that 26,600 women were treated for complications in Malawi in 2009 (Table 2). We obtained a slightly higher estimate of annual caseload $(30,600)$ when we averaged

*The DHS data on wantedness (wanted at the time, mistimed or unwanted) refers to births in the preceding three years. 
the two Health Facilities Survey estimates. The composite variable that averaged all three data sources yielded an estimate of 29,500 women treated for abortion complications. On average, 187 women were treated in each of the 166 facilities offering postabortion care in 2009; almost half of women who obtained such care did so at public hospitals, which treated a mean of 336 women per facility.

Of the 29,500 women treated for abortion complications, more than 12,100 received care in the Central region (41\%) and a similar number was treated in the South (Table 3). As noted earlier, an estimated 10,800 of the 29,500 women with complications were treated for spontaneous abortion; thus, we estimate that 18,700 women were treated in health facilities for complications of unsafe induced abortion.

For Malawi overall, the rate of treatment for complications for either type of abortion (induced or spontaneous) was 10.2 per 1,000 women aged 15-44 (not shown). The treatment rate was highest in the North (14.0) and lower in the Central region (10.0) and the South (9.3). The hospitalization rate for complications of unsafe induced abortion was 6.5 per 1,000 women aged 15-44 for the country as a whole; it was 9.7 in the North, 6.5 in the Central region and 5.6 in the South.

\section{Induced Abortion}

From the Health Professionals Survey, we estimated that $28 \%$ of women who had induced abortions in Malawi in 2009 were treated at a health facility; the corresponding multiplier was 3.6 (range, 2.6-4.6). Applying the multiplier to the estimated number of women treated for complications $(18,700)$ yields an estimate of 67,300 induced abortions (range, 48,600-86,000) in Malawi in 2009 (Table 4). This is equivalent to an annual induced abortion rate of 23 per 1,000 women aged 15-44 (range, 17-30 per 1,000). The estimated induced abortion ratio is 12 per 100 live births (range, 8-15 per 100). Regional differences in the rate and ratio were similar across measures; the North had the highest abortion rate ( 35 per 1,000 women) and ratio (17 per 100 live births).

\section{Unintended Pregnancy}

The overall pregnancy rate in Malawi in 2009 was 269 pregnancies per 1,000 women aged 15-44 (Table 5). This rate was slightly higher in the North (288) than in the Central region (271) and the South (260). The national unintended pregnancy rate was 139 per 1,000 women aged 15-44; the rate was slightly higher in the Central region (148) and lower in the North (128). Overall, 52\% of pregnancies in Malawi were unintended; again, the proportion was slightly higher than average in the Central region (54\%) and somewhat lower than average in the North (45\%).

\section{DISCUSSION}

This study is the first to estimate the incidence of abortion and unintended pregnancy in Malawi, nationally and regionally. Comparable studies that used the AICM to esti- mate abortion incidence in Sub-Saharan Africa have been conducted in the past few years in Burkina Faso, Ethiopia and Rwanda, and less recently in Nigeria and Uganda. ${ }^{15,17,25-27}$ All of these studies have included not only public-sector but also not-for-profit and private-sector facilities, thereby providing more comprehensive and accurate estimates of the number of women obtaining postabortion care, and, in turn, of overall abortion incidence.

Abortions are likely to be highly unreported in studies that measure abortion incidence using direct techniques (such as interviewing women or providers), especially in settings where abortion is legally restricted. ${ }^{28}$ As a result, indirect estimation techniques are accepted as the preferred approach for estimating abortion incidence in legally restrictive settings. The AICM has been widely used and found to yield robust estimates over time and across countries.

This is the second study, after a prior analysis of Ethiopia, ${ }^{15}$ to measure the number of women treated for postabortion care by combining two approaches: a Prospective Morbidity Survey that collects patient-specific data for a period of 2-4 weeks (30 days in the case of this study) and a Health Facilities Survey (the approach used by AICM studies), in which interviews with facility directors or other knowledgeable informants are used to obtain aggregate estimates of the number of women treated in each facility in the past month and in an average month. Use of these two different approaches produces a more robust estimate of this core input indicator for the estimation of abortion incidence, thus increasing one's confidence in the validity of the study results.

Our validity check revealed that logbook data, where available, more closely resembled Prospective Morbidity Survey caseload data than they did estimates from the Health Professionals Survey, indicating that logbooks may be a good source of caseload information and could be referred to when collecting information about women who receive postabortion care in Malawi. Further studies would allow researchers to explore the extent to which logbook data can be considered a comprehensive data source and could support caseload projections from provider estimates or other data collection tools used on a per-case basis.

The limitations of the AICM have been described elsewhere, ${ }^{19}$ they include the challenge of obtaining a quantitative multiplier from qualitative interviews with health professionals and the inability to verify a hospitalization rate for late miscarriages. We focus here on the specific challenges of applying the methodology in Malawi. Data quality will always be a concern; however, we feel that by using three sources of caseload information and the validity check, we were able to achieve and validate an annual estimate of the number of women treated for postabortion care that is more accurate than an estimate based on a single source. Although Malawi is a small country, some participants in the Health Professionals Survey may not have been highly knowledgeable about current conditions 
in rural areas, as three-fifths of them were working in urban areas. Future studies should identify and interview more key informants with recent rural experience. Finally, this study does not provide national estimates of the number of women treated at all facilities, but rather of women treated at facilities that were believed to be providers of postabortion care. If some facilities that were not known to provide postabortion care services were actually providing these services, our findings may underestimate the number of women treated for postabortion complications.

We estimated the abortion rate in Malawi in 2009 to be 23 per 1,000 women aged 15-44. The World Health Organization estimated the incidence rate for Africa as 28 and for the Eastern Africa subregion (which includes Malawi) as 36, indicating that our estimate is plausible and that Malawi may have a somewhat lower rate than is typical of Eastern Africa. ${ }^{1}$ Studies that used a comparable methodology have found similar abortion incidence rates in other African countries, including Burkina Faso (18 per 1,000), Ethiopia (23), Rwanda (25), Nigeria (25) and Uganda (56). ${ }^{15,17,25-27}$ The multipliers in these studies fall within a relatively narrow range (3.5-7.3) and are comparable to the value in our study (3.6), lending further support to our findings.

Interestingly, the abortion rate in Malawi was highest in the Northern region. DHS data suggest that married women in this region have greater access to family planning than do women elsewhere in Malawi; in 2010, only $24 \%$ of women in the North had an unmet need for family planning, compared with $27 \%$ and $26 \%$ in the Central and Southern regions, respectively. ${ }^{4}$ However, use of traditional methods, which have higher failure rates than modern methods, is higher in the North (about $8 \%$ of married women) than in the other two regions (where about 3\% of married women use these methods), perhaps accounting for part of the difference. ${ }^{4}$

Other DHS data from 2010 provide cultural and socioeconomic context surrounding these numbers. The proportion of women in the Central region who had had no schooling was four times that of women in the North, and at the national level, women with no education had had their first birth six years earlier than had women with more than a secondary education (at age 18 vs. age 24). Two in five women in the Central region had no exposure to newspapers, television or radio, compared with three out of 10 women in the North. Seventy percent of women in the North had been exposed to media-based family planning messages in the past few months, compared with only $58 \%$ of women in the Central region. Therefore, compared with their counterparts in the North, women in the Central region are less educated-both in general and in terms of family planning-and have less exposure to informational resources, including those that provide family planning messages. ${ }^{4}$

According to the United Nation's Millennium Development Goals monitor, Malawi is "off track" for achieving goal 5-a 75\% reduction in maternal mortality between
1990 and 2015. ${ }^{29}$ Global recommendations include taking three major steps to improve maternal and reproductive health for women: increasing access to family planning; improving access to quality care during pregnancy and childbirth; and increasing access to safe abortion services (to the extent allowed by the law), including provision of postabortion care for women with complications of induced and spontaneous abortions. ${ }^{30}$

Sexually active Malawian women, regardless of age or marital status, need greater access to family planning services and contraceptive choices. In 2010, 46\% of married women reported currently using contraceptives, but an additional $26 \%$ had an unmet need for family planning. ${ }^{4}$ Although the use of modern methods by married women rose from $28 \%$ in 2004 to $42 \%$ in 2010 , our study found a high unintended pregnancy rate of 139 per 1,000 women aged 15-44.,5 These figures illustrate that women need better access to contraceptive services (including information about and access to a range of methods) to increase the level of use and to reduce the incidence of contraceptive failure resulting from inconsistent and incorrect use. Young women are especially in need of such services, as $15 \%$ of unmarried women aged $15-24$ are sexually active, ${ }^{4}$ and half of all women seeking postabortion care in Malawi are aged $15-24$ years. ${ }^{31}$

As part of an initiative that was started in 2003, the Reproductive Health Unit of the Malawi Ministry of Health has been increasing, through provider training and facility upgrades, the number of public facilities that provide postabortion care. Continuation of such efforts is needed to ensure that trained providers and equipped facilities are paired and distributed in such a way as to provide high quality coverage for postabortion care throughout the country. In addition, trained providers need constant access to the tools that are critical for reducing maternal mortality: short- and long-term contraceptive methods for the prevention of unwanted pregnancy, misoprostol for treatment of postpartum hemorrhage, and manual vacuum aspiration and misoprostol for the treatment of incomplete abortion.

Unsafe abortion can lead to maternal mortality, and Malawi has one of the highest maternal mortality rates in the world; $18 \%$ of maternal deaths in the country are attributable to unsafe abortion. ${ }^{l}$ The findings of this study warrant careful consideration as the government and civil society organizations in Malawi continue efforts to achieve the Millennium Development Goals and improve the health of women and their families. At a minimum, needed measures include continued improvements in access to contraceptive services, with a special focus on information and services for young people both in and out of school, as well as training in abortion-related care for health care providers in the public and private sectors. Reforming the abortion law to allow explicitly for more indications for legal induced abortion, and making these services available, would reduce the number of women who have complications of unsafe induced abortion. The health of women 
and their families in Malawi deserves the highest priority. Because of a restrictive abortion law, almost 70,000 women in Malawi every year are risking their health and their lives by having a clandestine abortion.

\section{REFERENCES}

1. World Health Organization (WHO), Unsafe Abortion: Global and Regional Estimates of the Incidence of Unsafe Abortion and Associated Mortality in 2008, sixth ed., Geneva: WHO, 2011.

2. Shah I and Ahman E, Unsafe abortion: global and regional incidence, trends, consequences, and challenges, Journal of Obstetrics and Gynaecology Canada, 2009, 31(12):1149-1158.

3. WHO et al., Trends in Maternal Mortality: 1990 to 2008, Geneva: WHO, 2010

4. Malawi National Statistical Office and MEASURE DHS, Malawi Demographic and Health Survey 2010, Zomba, Malawi: Malawi National Statistical Office and MEASURE DHS, 2010.

5. Malawi National Statistical Office and ORC Macro, Malawi Demographic and Health Survey 2004, Zomba, Malawi: Malawi National Statistical Office; and Calverton, MD, USA: ORC Macro, 2005.

6. Lema VM et al., Maternal mortality at the Queen Elizabeth Central Teaching Hospital, Blantyre, Malawi, East African Medical Journal, 2005, 82(1):3-9.

7. Sedgh $\mathrm{G}$ et al., Induced abortion: incidence and trends worldwide from 1995 to 2008, Lancet, 2012, 379(9816):625-632

8. WHO, Unsafe Abortion: Global and Regional Estimates of the Incidence of Unsafe Abortion and Associated Mortality in 2003, fifth ed., Geneva: WHO, 2007.

9. Malawi Penal Code (1930), Sections 149-151 and 243, Cap. 7:01.

10. Family Planning Association of Malawi, Magnitude, views and perceptions of people on abortion and post abortion care services in four Malawian districts, paper presented at the Third African Conference on Sexual Health and Rights, Abuja, Nigeria, Feb. 4-7, 2008.

11. Munthali A et al., Adolescent sexual and reproductive health in Malawi: results from the 2004 National Survey of Adolescents, Occasional Report, New York: Guttmacher Institute, 2006, No. 24.

12. Lema VM and Thole G, Incomplete abortion at the teaching hospital, Blantyre, Malawi, East African Medical Journal, 1994, 71(11):727-735.

13. Gebreselassie $\mathrm{H}$ et al., Caring for women with abortion complications in Ethiopia: national estimates and future implications, International Perspectives on Sexual and Reproductive Health, 2010, 36(1):6-15.

14. Jewkes $\mathrm{R}$ et al., Prevalence of morbidity associated with abortion before and after legalisation in South Africa, BMJ, 2002, 324(7348):1252-1253.

15. Singh $S$ et al., The estimated incidence of induced abortion in Ethiopia, 2008, International Perspectives on Sexual and Reproductive Health, 2010, 36(1):16-25.

16. Gebreselassie $\mathrm{H}$ et al., The magnitude of abortion complications in Kenya, BJOG, 2005, 112(9):1229-1235.

17. Singh $S$ et al., The incidence of induced abortion in Uganda, International Family Planning Perspectives, 2005, 31(4):183-191.

18. Fetters T, Prospective approach to measuring abortion-related morbidity: individual-level data on postabortion patients, in: Singh S, Remez L and Tartaglione A, eds., Methodologies for Estimating Abortion Incidence and Abortion-Related Morbidity: A Review, New York: Guttmacher Institute, 2010, pp. 135-146.

19. Singh S, Prada E and Juarez F, The Abortion Incidence Complications Method: a quantitative technique, in: Singh S, Remez L and Tartaglione A, eds., Methodologies for Estimating Abortion Incidence and Abortion-Related Morbidity: A Review, New York: Guttmacher Institute, 2010, pp. 71-98.
20. Malawi National Statistical Office, 2008 Population and Housing Census Results, Lilongwe, Malawi: National Statistical Office, 2008

21. Malawi National Statistical Office and United Nations Children's Fund (UNICEF), Malawi Multiple Indicator Cluster Survey 2006: Final Report, Lilongwe, Malawi: Malawi National Statistical Office and UNICEF, 2008

22. National Statistical Office, Malawi Second Integrated Household Survey, 2004-2005, Zomba, Malawi: National Statistical Office, 2005.

23. Bongaarts J and Potter RG, Fertility, Biology and Behavior: An Analysis of the Proximate Determinants, New York: Academic Press, 1983

24. Harlap S, Shiono PH and Ramcharan S, A life table of spontaneous abortions and the effects of age, parity and other variables, in: Hook EB and Potter I, eds., Human Embryonic and Fetal Death, New York: Academic Press, 1980, pp. 145-158.

25. Sedgh $\mathrm{G}$ et al., Estimating abortion incidence in Burkina Faso using two methodologies, Studies in Family Planning, 2011, 42(3):147154

26. Basinga $\mathrm{P}$ et al., Abortion incidence and postabortion care in Rwanda, Studies in Family Planning, 2012, 43(1):11-20.

27. Henshaw $S$ et al., The incidence of induced abortion in Nigeria, International Family Planning Perspectives, 1998, 24(4):156-164.

28. Rossier C, Estimating induced abortion rates: a review, Studies in Family Planning, 2003, 34(2):87-102

29. United Nations, MDG monitor: Malawi, 2010, <http://www.mdgmonitor.org/country_progress.cfm?c=MWI\&cd $=454>$, accessed July $18,2010$.

30. Women Deliver, Focus on 5: women's health and the MDGs, 2010, $<$ http://www.womendeliver.org/knowledge-center/publications/ focus-on-5>, accessed July 15, 2010.

31. Levandowski BA, Reproductive health characteristics of young Malawian women seeking post-abortion care, African Journal of Reproductive Health, 2012, 16(2):253-261.

\section{RESUMEN}

Contexto: El aborto está legalmente restringido en Malaui y no hay datos disponibles sobre la incidencia del procedimiento. Métodos: Se aplicó la Metodología sobre complicaciones relacionadas con la incidencia del aborto para estimar los niveles de aborto inducido en Malaui en 2009. Los datos relacionados con la provisión de la atención postaborto fueron recolectados de 166 instituciones de salud públicas, no gubernamentales y privadas. Asimismo, 56 informantes clave proporcionaron estimaciones sobre la probabilidad de que las mujeres que tienen abortos experimenten complicaciones y busquen atención médica. Se usaron los datos de estas encuestas y de la Encuesta Demográfica y de Salud de Malaui de 2010 para calcular tasas y razones de aborto, así como tasas de embarazo y de embarazo no planeado.

Resultados: Se estima que en 2009 unas 18.700 mujeres en Malaui recibieron tratamiento en instituciones de salud por complicaciones relacionadas con el aborto inducido. Un número estimado de 67.300 abortos inducidos fueron practicados, lo que equivale a una tasa de 23 abortos por 1.000 mujeres en edades de 15-44 años y una razón de aborto de 12 por 100 nacidos vivos. La tasa de aborto fue más alta en la región Norte (35 por 1.000) que en las regiones Central o Sur (20-23 por 1.000). La tasa anual de embarazo no planeado en 2010 fue de 139 por 1.000 mujeres en edades de 15-44 años, y se estima que un $52 \%$ del total de los embarazos no fueron planeados. 
Conclusión: El aborto inseguro es común en Malaui. Se necesitan intervenciones para ayudar a las mujeres y parejas a evitar el embarazo no planeado, reducir la necesidad del aborto inseguro y disminuir la mortalidad materna.

\section{RÉSUMÉ}

Contexte: L'avortement est limité par la loi au Malawi et aucune donnée n'est disponible sur l'incidence de la procédure.

Méthodes: La méthode AICM (Abortion Incidence Complications Methodology) a été utilisée pour estimer les niveaux de l'avortement provoqué au Malawi en 2009. Les données de prestation de soins après avortement ont été collectées auprès de 166 établissements de santé publics, non gouvernementaux et privés et les estimations de la probabilité de complications et de demande de soins parmi les femmes ayant subi un avortement ont été obtenues de 56 témoins privilégiés. Les données obtenues de ces enquêtes et de l'Enquête démographique et de santé 2010 du Malawi ont servi à calculer les taux d'avortement, de grossesse et de grossesse non planifiée.

Résultats: Selon les estimations, 18.700 femmes ont été traitées dans les établissements de santé du Malawi pour complications d'un avortement provoqué en 2009. Le nombre d'avortements pratiqués est estimé à 67.300, soit un taux de 23 avortements pour mille femmes âgées de 15 à 44 ans et un ratio de 12 avortements pour cent naissances vivantes. Le taux d'avortement est supérieur dans la région du nord (35 pour mille), par rapport à celle du centre ou du sud (20-23 pour mille). Le taux annuel de grossesse non planifiée a été calculé en 2010 à 139 pour mille femmes âgées de 15 à 44 ans et les grossesses non planifiées sont estimées à $52 \%$ de l'ensemble des grossesses.

Conclusions: L'avortement non médicalisé est fréquent au Malawi. Des interventions sont nécessaires pour aider les femmes et les couples à éviter les grossesses non désirées, réduire le recours à l'avortement non médicalisé et faire baisser la mortalité maternelle.

\section{Acknowledgments}

This research was funded primarily by the Consortium for Research on Unsafe Abortion in Africa and its principal donor, the UK Department for International Development. Additional funding was provided by UNFPA Malawi.

Author contact: levandowskib@ipas.org 